\title{
Use of the Hole-drilling Method for Measuring Residual Stresses in Highly Stressed Shot-peened Surfaces
}

\author{
by J. P. Nobre, M. Kornmeier, A. M. Dias and B. Scholtes
}

\begin{abstract}
The same shot-peening treatment was applied to five steels with different mechanical properties. The induced residual stress profiles were analyzed using $X$-ray diffraction and incremental hole drilling (IHD). The results of both techniques showed that IHD can still be successfully used for measuring shot-peening residual stresses, even if these exceed the yield strength of the bulk material. Expected errors due to the plasticity effect are reduced by the strain hardening of the surface. For an assessment of the reliability of IHD data, strain-hardening variation was quantified by microhardness measurements to estimate the yield strength of the plastified layer. All the main calculation methods for IHD were applied. The results were compared and discussed with respect to the characteristics of each method.
\end{abstract}

KEY WORDS-Residual stresses, incremental hole drilling, shot peening, plasticity effect, $\mathrm{X}$-ray diffraction

Residual stresses are present in most mechanical components due to production processes or service loading. Because residual stresses can have either beneficial or detrimental effects, the exact knowledge and control of residual stress state and in-depth distribution are of high practical relevance.

The incremental hole-drilling (IHD) technique and the Xray diffraction (XRD) $\sin ^{2} \psi$ method find broad acceptance among the quantitative in-depth residual stress measurement methods. A comparison of studies that apply both methods simultaneously, however, leads to quite inconsistent findings. In some cases, a relatively good agreement between the results of both measurement techniques is reported. 1,2 On the other hand, comparable results are often found only in the interior of the samples; ${ }^{3-6}$ the near-surface regions and strong stress gradients seem to be problematic for the holedrilling method. For that reason, residual stress distributions obtained by the IHD method are frequently completed by additional XRD measurements on the surface. ${ }^{7-10}$ In Ref. 11, however, the IHD method was found to be unsuitable for accessing residual stress gradients in the case of a deep-rolled aluminum alloy.

J.P. Nobre is a Research Assistant, Departamento de Engenharia Mecânica, Universidade de Coimbra, P-3030 Coimbra, Portugal. M. Kornmeier is a researcher (Post-Doc), Departamento de Engenharia Mecânica, Universidade de Coimbra, P-3030 Coimbra, Portugal. A. M. Dias is an Associate Professor, Departamento de Engenharia Mecânica, Universidade de Coimbra, P-3030 Coimbra, Portugal. B. Scholtes is a Professor, Institut fuir Werkstofftechnik, Universität Gh Kassel, 34125 Kassel, Germany.

Original manuscript submitted: April 8, 1999.

Final manuscript received: April 25, 2000.
A systematic comparison of both methods was carried out in a recent survey. ${ }^{12}$ Observed discrepancies are often attributed to the basic shortcoming of the hole-drilling method, which is its limitation to residual stresses up to 60 percent of the material's yield strength. ${ }^{12-15}$ Higher residual stresses lead to local plastic deformations caused by the stress concentration of the drilled hole itself, which depends on the stress state. For the equibiaxial stress state, the stress concentration factor of a through hole is 2, compared with even higher values of other stress states. As with drilling-induced plastic deformations, this so-called plasticity effect can strongly affect the residual stress evaluation, which assumes linearelastic material behavior. An estimation of the related error (overestimation of residual stresses) is difficult, since the local yield strength of the interesting near-surface layers can differ significantly from the bulk material's value due to the prior surface treatment and the strain-hardening capacity of the respective material. Hardness measurements can, however, be used to estimate the strain-hardening effect.

In this context, the aim of the present work is to show, for the example of shot-peening residual stresses, in which cases the results of the IHD and XRD methods can be compared directly and when discrepancies may be expected. A uniform shot-peening treatment was applied to five steels with differing mechanical properties. The obtained residual stress gradients were systematically analyzed by both methods. Results will be discussed with respect to their measurement principles and limitations. Concerning the hole-drilling results, the influence of both the plasticity effect and the residual stress evaluation procedure will be especially considered. Residual stress in-depth evaluation was carried out using different software: the differential method (MPA Stuttgart), ${ }^{16}$ the average stress method (ReStress), ${ }^{15,17}$ the power series method and the integral method (H-DRILL). ${ }^{18}$

\section{Estimate of the Yield Strength from Hardness Data}

Any criterion to assess the relevance of the plasticity effect on IHD results should take the material's strain-hardening capacity into account to estimate the local yield strength. According to Tabor, ${ }^{19}$ "A convenient method of measuring the elastic limit of a material is to determine its hardness using a pyramidal indenter possessing a large apex angle, as in the Vicker's test." His theory on the hardness of metals is founded on experimental evidence. Tabor observed that when a metal is submitted to high cold working, that is, without capacity for subsequent work hardening, plastic flow begins when the mean contact pressure is given by $p_{m}=c \sigma_{r}$, where $c$ is a constant about 3 and $\sigma_{r}$ is a representative yield stress. ${ }^{19}$ Based 
on this theory, Tabor formulated an equation to estimate the ultimate strength of a material. Several attempts have been made to estimate the 0.2 percent offset yield strength. George et al. ${ }^{20}$ proposed a method using the Rockwell hardness data. Using Vicker's and Meyer's hardness, Cahoon et al $^{21}$ found an empirical equation that allows the calculation of the yield strength without needing to know its stress-strain curve, given by $\sigma_{y}=(H / 3) \cdot(0.1)^{\mathrm{m}-2}$. In this equation, $\sigma_{y}$ is the yield strength, $H$ is the Vicker's hardness and $m$ is the Meyer's exponent (the strain-hardening coefficient can be related to this exponent by $n=m-2) .{ }^{19}$ Cahoon et al. ${ }^{21}$ showed the equation's validity in a $65 \mathrm{~S}$ aluminum alloy and 1040 steel subjected to various amounts of cold working. This empirical equation clearly shows proportionality between $\sigma_{y}$ and $H$. Consequently, if hardness varies to a certain degree, the yield strength should vary correspondingly.

\section{Residual Stress Analysis Methods}

\section{Incremental Hole-drilling Method: Principle, Plasticity Effect and Comparison of Calculation Procedures}

The hole-drilling method ${ }^{22}$ basically consists of machining a small hole in the surface of the test material and measuring the surface strain relaxation due to the presence of the hole. ${ }^{23}$ The theory of elasticity is used to correlate the strain relaxation and the residual stresses existing prior to hole drilling. For that reason, local yielding caused by the stress concentration around the hole can affect the residual stress calculation. This effect becomes significant when residual stresses reach about 60 percent of the material's yield strength. ${ }^{12-15}$ According to Ref. 14, for example, for residual stresses of 70 percent yield strength, an error of 15 percent can be expected in stress calculation. An overestimation of 20 percent for residual stresses reaching 90 percent yield strength is given in Ref. 24. In Ref. 25, an error of 35 percent was calculated for a stress level of 95 percent yield strength.

The measurement of in-depth nonuniform residual stresses requires incremental drilling. Currently, four basically different methods are used to calculate nonuniform residual stresses: the integral method, $2,18,26,27$ the incremental strain method, ${ }^{28}$ the power series method ${ }^{29}$ and the average stress method. ${ }^{17}$

Others ${ }^{16,30}$ have proposed calculation procedures that can mainly be considered as modifications to the methods referred to above. In the 1950 s, Kelsey ${ }^{28}$ proposed the incremental strain method (differential method ${ }^{16}$ ) to evaluate in-depth nonuniform residual stresses. The method is based on the relationship between surface strain relaxation and hole depth for a known uniform stress field and the correlation of these data with those obtained by drilling a hole in an unknown nonuniform stress field. In the 1970s, BijakZochowski ${ }^{26}$ pointed out that the incremental strain method neglects the additional strain relaxation of the stresses existing in the previous increments, caused only by the increase in hole depth, and proposed the integral method. This method assumes that the strain relief at the material's surface is the accumulated result of the residual stresses originally existing in the zone of each successive increment along the total hole depth. In 1981, Schajer ${ }^{29}$ introduced an alternative procedure called the power series method. The method assumes that the residual stress field can be divided into power series components. In general, only two power series terms can be used, which implies an in-depth linear stress field. ${ }^{18}$ In 1986 , Nickola ${ }^{17}$ introduced the average stress method, defining an equivalent uniform stress to take the influence of the residual stresses in previous increments into account. This concept is based on the average stress within the total hole depth, which produces the same total strain relief as the actual nonuniform stress field.

The influence of calculation procedures on residual stress results has been analyzed by several authors ${ }^{18,31-33}$ using the finite element method. Schajer ${ }^{18}$ concluded that the integral method is a good stress evaluation method when strong stress gradients are present. However, this method implies very precise measurements of relieved strains and depths for each incremental step. Calculation results are very sensitive to measurement errors because of propagation effects. Error sensitivity is proportional to the number of hole depth increments (the inverse is true for the power series method). ${ }^{34}$ For this reason, the integral method should be used with a few large depth increments. In a comparison of residual calculation procedures, Kockelmann and Schwarz ${ }^{31}$ concluded that the differential method (MPA II) and the integral method (Ontario-Hydro ${ }^{27}$ ) are the most suitable methods for the analysis of complex residual stress states.

The limitations of the incremental strain method and the average stress method have also been discussed in detail by Flaman et al. ${ }^{33}$ The incremental strain method assumes that 100 percent of each measured strain increment is caused by the stress in the actual drilling step. Assuming a uniform residual stress field, a hole diameter of $D=1.6 \mathrm{~mm}$ and seven equal drilling step sizes of $\Delta z=0.25 \mathrm{~mm}$, up to a depth of $z / D=1$, Flaman et al. showed that for the increment at $z / D=0.625$, only about 13 percent of the strain relief is caused by the stress in that depth increment. In the average stress method, the concept of an equivalent uniform stress that produces the same strain increment as the real nonuniform stress field implies that stresses at all given depth increments contribute equally to the strain relief measured at the surface. However, residual stresses existing in the increments close to the surface contribute much more to the strain relaxation than those in deeper increments. ${ }^{32,33}$

All methods are limited by the decreasing sensitivity to stress relief at deeper increments (maximum depths up to about 0.35 times as deep as the mean strain gage rosette radius used). ${ }^{18,32}$

\section{Principle of the X-ray Diffraction Method}

Residual stresses can be analyzed nondestructively by the XRD method, which measures lattice deformations of crystalline materials, with the lattice distance of specific $\{h k l\}$ planes as gage lengths. For a material without any residual stress, the lattice deformations are independent of the orientation of the diffracting $\{h k l\}$ planes relative to the sample's surface. If the material is submitted to a stress, the lattice deformation becomes a function of the orientation according to linear elasticity. It is possible to relate the orientationdependent variation of the lattice deformation to the underlying stress state. Because lattice deformations are determined, plane-specific X-ray elastic constants have to be used. Assuming the plane stress condition (due to the shallow penetration depth of X-rays in metallic materials), the so-called $\sin ^{2} \psi$ method ${ }^{35}$ can be used to determine the corresponding residual stresses of the surface of crystalline materials. 


\section{Materials and Experimental Procedure}

Five steels with different mechanical properties (see Table 1) were machined in flat plates of $12 \mathrm{~mm}$ thickness. The dimensions chosen for the samples were sufficiently large to avoid edge effects. ${ }^{23}$ After grinding, all specimens were subjected to an identical shot-peening treatment. Table 2 shows the shot-peening parameters used.

IHD and XRD techniques were used to characterize the residual stress depth distribution in the center of each sample. For the IHD technique, high-speed drilling equipment (milling guide RS-200 with air turbine, Measurements Group Inc.) was used to create a cylindrical blind hole. This technique is recommended because only minor drilling-induced plastic deformations occur and a satisfying hole shape can be achieved. ${ }^{36}$ Surface strain relief was measured by a threeelement strain gage rosette (CEA-06-062UM-120, Measurements Group Inc.), the gages being radially oriented around the hole at different angular positions. In depth increments of $0.02 \mathrm{~mm}$ to $0.08 \mathrm{~mm}$, strain relief was measured after each depth increment to about $1 \mathrm{~mm}$ below the surface. Smaller steps were carried out close to the surface to access stress gradients more precisely. The typical hole diameter was about $1.8 \mathrm{~mm}$. For the residual stress evaluation, the elastic constants $E=210000 \mathrm{MPa}$ and $\nu=0.3$ were used.

XRD residual stress analysis was combined with the electrolytic layer removal technique to achieve residual stress depth profiles. Stress relaxation due to layer removal was not taken into account, since the affected region was small and no significant relaxation effects could be expected. Lattice deformations of the $\mathrm{Fe}\{211\}$ planes were determined on a conventional $\Omega$-diffractometer for $11 \psi$-angles between $-45 \mathrm{deg}$ and $45 \mathrm{deg}$ using $\mathrm{CrK} \alpha$ radiation. Residual stresses were calculated for the plain stress condition using X-ray elastic constants of $1 / 2 s_{2}=5.832 \times 10^{-6} \mathrm{MPa}^{-1}$ and $s_{1}=-1.272 \times 10^{-6} \mathrm{MPa}^{-1}$.

\section{Experimental Results}

The left-hand side of Fig. 1 shows typical strain relaxation curves as a function of the drilling depth. The relieved strains are independent of the measurement direction, indicating an equibiaxial stress state typical of shot-peening residual stresses. This was confirmed by the residual stress results obtained for all samples. Hence, in the following graphs, only one stress component will be presented, corresponding to the maximum principal stress value. The right-hand side of Fig. 1 shows the respective in-depth profiles of the microhardness and the integral diffraction peak width. Both profiles show the influence of strain hardening in the near-surface layers. Microhardness and peak width profiles indicate maximum values at the surface and decrease continuously toward the interior of the specimen. A similar behavior can be observed for both profiles, each one allowing the approximate determination of the dimension of the plastified depth where the bulk material's values are achieved. In this way, the strainhardening effect can be estimated.

Four calculation procedures were used to determine indepth residual stress distribution by IHD. Because a strong residual stress gradient could be expected close to the surface, measurements were carried out with small depth increments $(0.02 \mathrm{~mm})$ for the first drilling steps, below those recom- mended by, for example, TN-503 (>0.13 mm). ${ }^{15}$ The MPA differential method provides spline functions to smooth the initial strain data to reduce statistical errors. The MPA data evaluation, merely performing a slight smoothing of the original strain data, led to consistent results. Respective residual stresses were assigned to the beginning of each drilling step. For evaluations with the average stress and the integral method, however, a larger step size had to be used to overcome the higher error sensitivity ${ }^{18}$ and the related scattering of residual stress results. For these methods, respective residual stress values were assigned as average values to the center of each step. The power series method, only calculating linear distributions, correspondingly allows the approximation of the residual stress distributions as straight lines.

Figures 2-6 show the in-depth residual stress and microhardness profiles obtained in the experiments. The figures are presented in the order of increasing 0.2 percent offset yield strength of the bulk material. To discuss the influence of the plasticity effect on the residual stress values obtained by IHD, in each figure the yield strength of the bulk material and 60 percent of this value are included as horizontal lines and the plastified depth due to the shot-peening treatment is included as a vertical line. The extent of the plastified depth was determined according to the peak width variation. Residual stress values obtained by XRD were used as a reference value for results obtained by IHD.

Maximum compressive residual stresses obtained using XRD vary between $-500 \mathrm{MPa}$ and $-600 \mathrm{MPa}$ for all specimens. For specimens 1,4 and 5, the maximum values appear at the surface (Figs. 2, 5 and 6). For specimens 2 and 3 (Figs. 3 and 4), XRD shows maximum compressive residual stresses ( -550 and $-500 \mathrm{MPa}$, respectively) just below the surface, at about $0.020 \mathrm{~mm}$ and $0.040 \mathrm{~mm}$, respectively, representing a strong residual stress gradient within the first two drilling steps. IHD, however, always led to compressive maximum residual stresses at the surface. The evaluation of IHD strain data with the differential method, allowing a better depth resolution compared with the average stress and the integral method, is still not able to detect the residual stress variations obtained by XRD just below the surface. With regard to the fact that the residual stresses obtained by IHD represent a mean value over each depth increment, this method is evidently not able to detect such rapid residual stress variation correctly. Furthermore, the first increment size is always associated with less accuracy (roughness, zero depth), thus increasing the uncertainty in the residual stress determination of surface values by IHD.

As shown in Figs. 2-6, except for specimen 3 (Fig. 4), quite good correlation between the XRD and IHD results was obtained near the material's surface (less than 0.3-0.4 mm depth). In this region, the IHD results obtained by the differential method always show the best fit to XRD results whereas the integral and the average stress methods lead to a slight overestimation of residual stresses. In deeper layers (greater than 0.3-0.4 mm depth), however, the differential method and the average stress method show a distinct overrating of residual stress values. These two methods still indicate residual stresses of about -100 MPa where XRD already detects only negligible values. Here, the integral method is in much better agreement with the XRD results than the other IHD calculation procedures, which was theoretically expected. ${ }^{18}$ Finally, the linear residual stress distributions given by the power series method can be considered a relatively good 
TABLE 1-MATERIALS: MECHANICAL PROPERTIES AND CHEMICAL COMPOSITION

\begin{tabular}{|c|c|c|c|c|c|c|c|c|c|c|c|}
\hline \multirow{2}{*}{$\begin{array}{l}\text { Steel } \\
\text { (AISI) }\end{array}$} & \multirow{2}{*}{$\begin{array}{l}\sigma_{y 0.2^{a}} \\
(\mathrm{MPa})\end{array}$} & \multirow{2}{*}{$\begin{array}{c}\sigma_{m}^{a} \\
(\mathrm{MPa})\end{array}$} & \multirow[b]{2}{*}{$n^{\mathrm{a}}$} & \multirow{2}{*}{$\begin{array}{l}\text { Hardness } \\
(H V)\end{array}$} & \multicolumn{7}{|c|}{ Chemical Composition (\% weight) } \\
\hline & & & & & $\mathrm{C}$ & $\overline{S i}$ & $\mathrm{Mn}$ & $\mathrm{Cr}$ & Mo & $\mathrm{Ni}$ & $\mathrm{V}$ \\
\hline $\begin{array}{l}1-1045 \\
2-(420) \\
3-3415 \\
4-9255 \\
5-4337\end{array}$ & $\begin{array}{c}415 \\
425 \\
445 \\
520 \\
1120\end{array}$ & $\begin{array}{c}700 \\
680 \\
670 \\
850 \\
1220\end{array}$ & $\begin{array}{l}0.27 \\
0.21 \\
0.17 \\
0.25 \\
0.07\end{array}$ & $\begin{array}{l}240 \\
220 \\
230 \\
260 \\
380\end{array}$ & $\begin{array}{l}0.45 \\
0.38 \\
0.14 \\
0.55 \\
0.34\end{array}$ & $\begin{array}{c}<0.4 \\
0.9 \\
<0.4 \\
1.65 \\
<0.4\end{array}$ & $\begin{array}{c}0.65 \\
0.5 \\
0.55 \\
0.85 \\
0.65\end{array}$ & $\begin{array}{l}13.6 \\
0.75 \\
1.50\end{array}$ & 0.22 & $\begin{array}{l}3.25 \\
1.50\end{array}$ & 0.3 \\
\hline
\end{tabular}

a. Uniaxial tensile tests (ASTM E 8) - strain hardening exponent obtained according to ASTM E 646

b. Producer data

TABLE 2-SHOT-PEENING PARAMETERS (ACCORDING TO MIL-S-13165 C)

\begin{tabular}{cccc}
\hline Peening Medium & Impact Angle & Almen Intensity & Coverage \\
\hline S170 & $\pm 90 \mathrm{deg}$ & $14 \mathrm{~A}$ & 100 percent
\end{tabular}
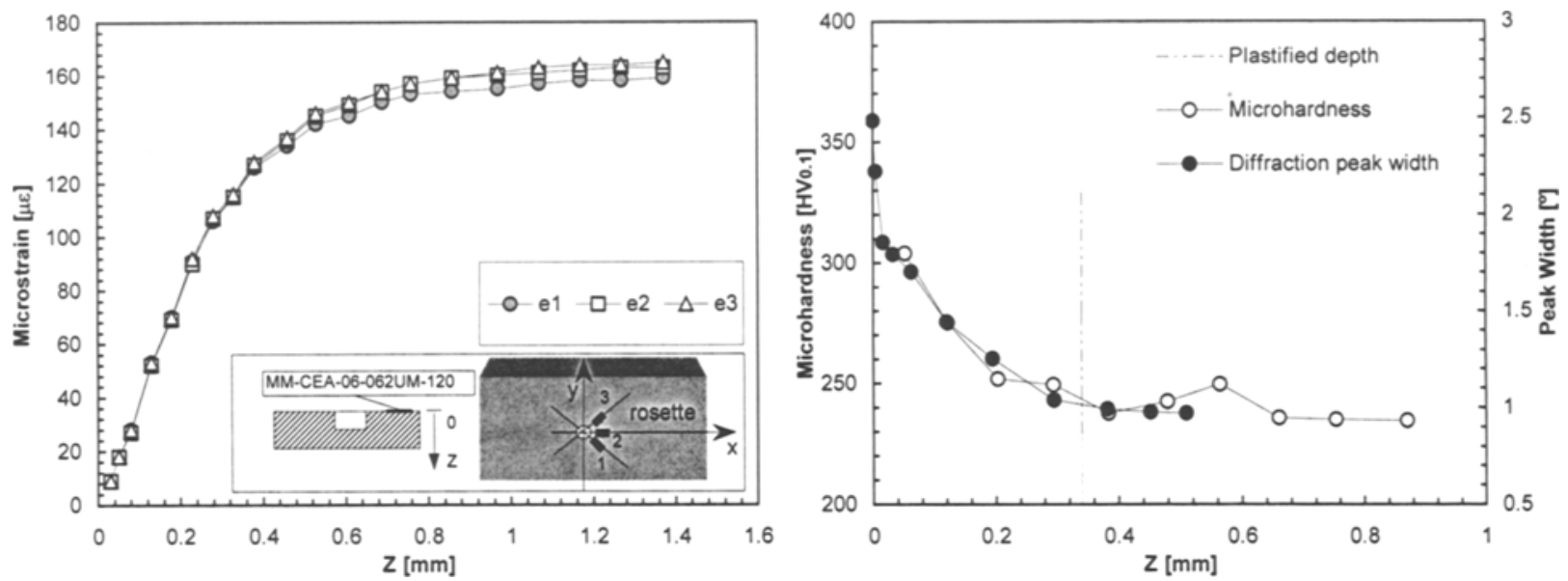

Fig. 1-Measured relieved strains in AISI 1045 shot-peened steel specimen (left). Corresponding profiles of microhardness and diffraction peak width (right)
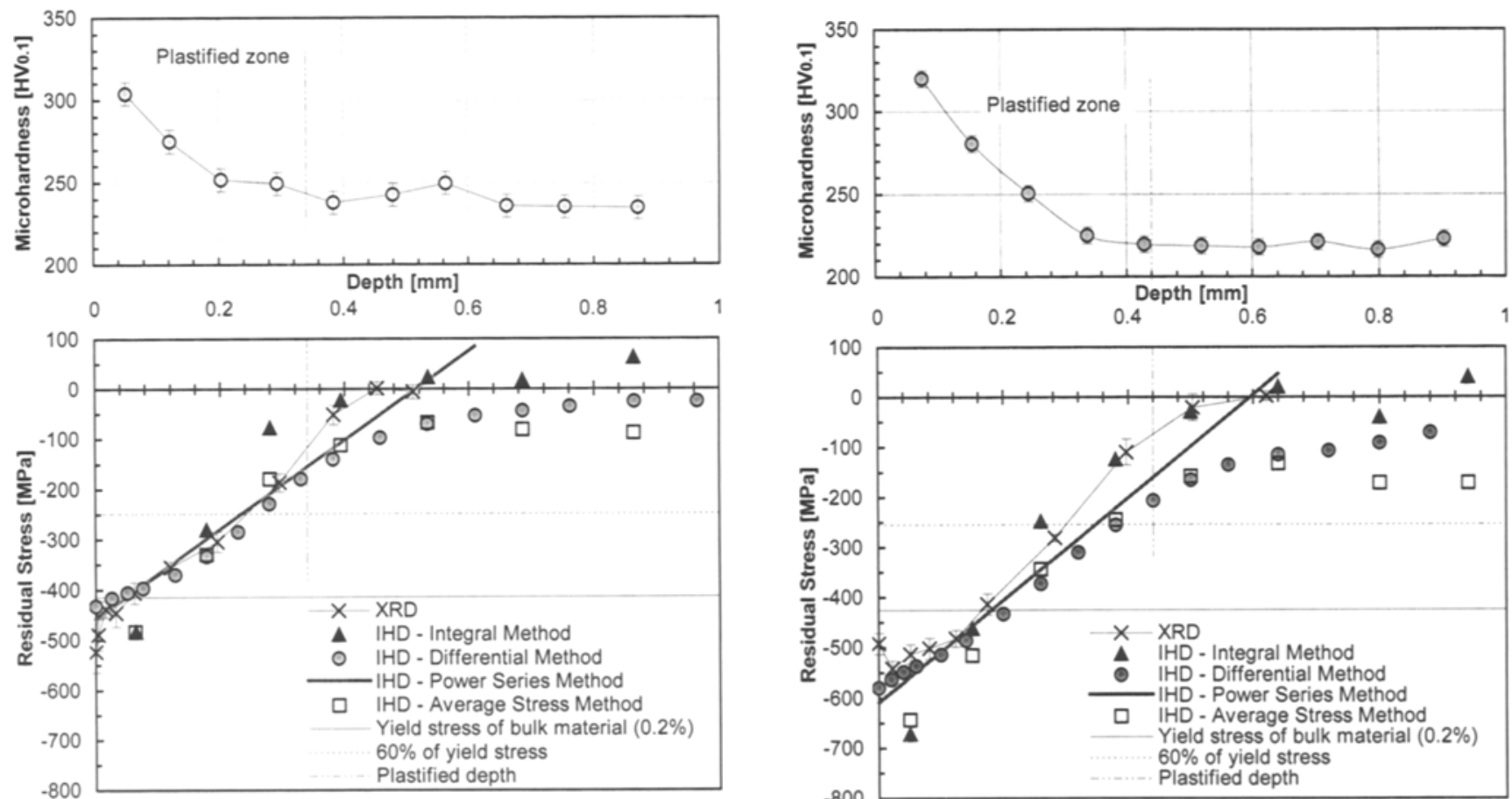

Fig. 2-Residual stresses, microhardness profile and plastified depth in specimen 1 (AISI 1045): comparison between incremental hole-drilling (IHD) and X-ray diffraction (XRD) results

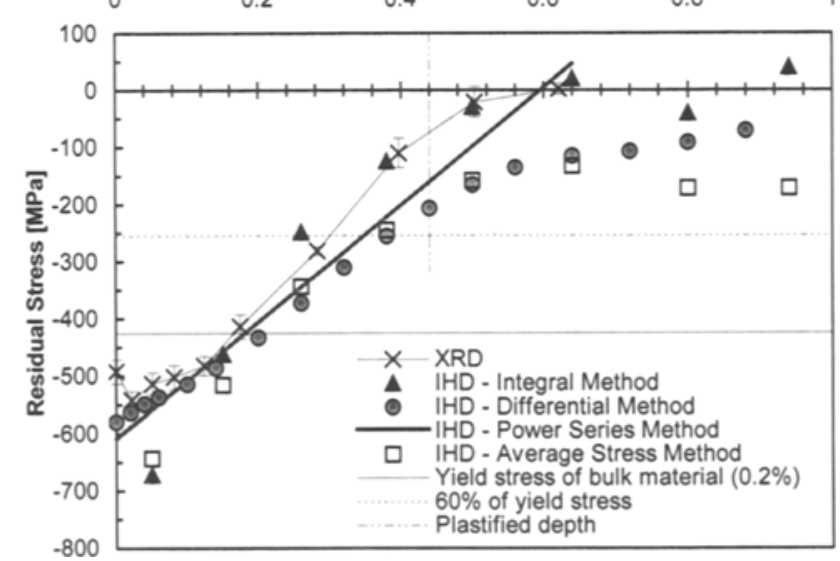

Fig. 3-Residual stresses, microhardness profile and plastified depth in specimen 2 (AISI 420): comparison between incremental hole-drilling (IHD) and X-ray diffraction (XRD) results 

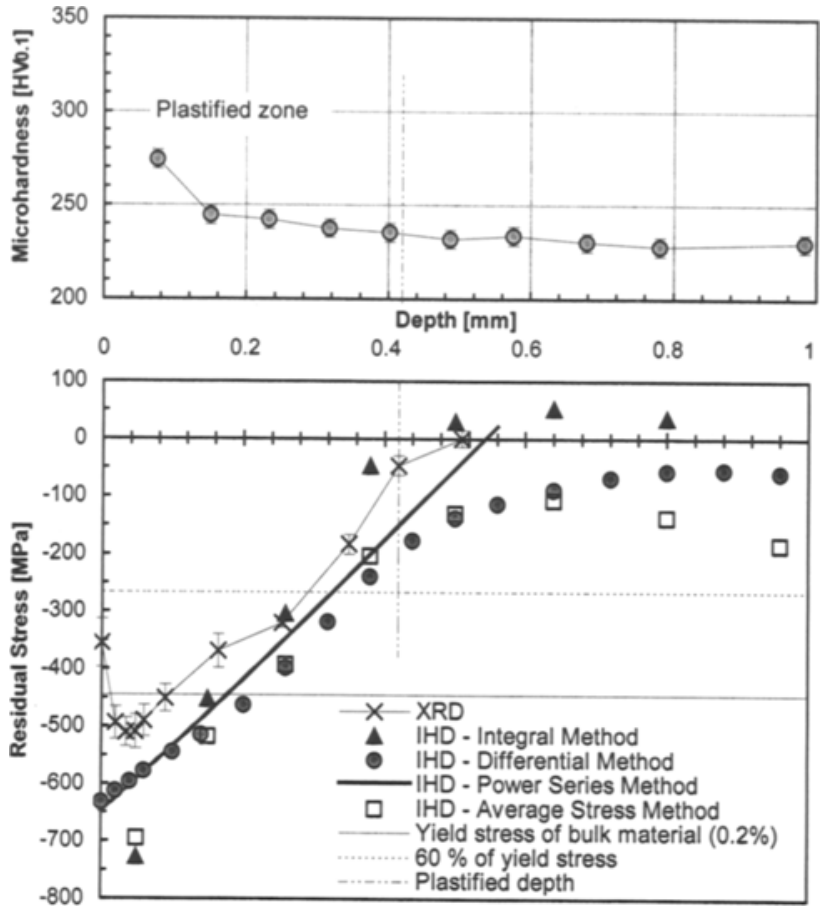

Fig. 4-Residual stresses, microhardness profile and plastified depth in specimen 3 (AISI 3415): comparison between incremental hole-drilling (IHD) and X-ray diffraction (XRD) results
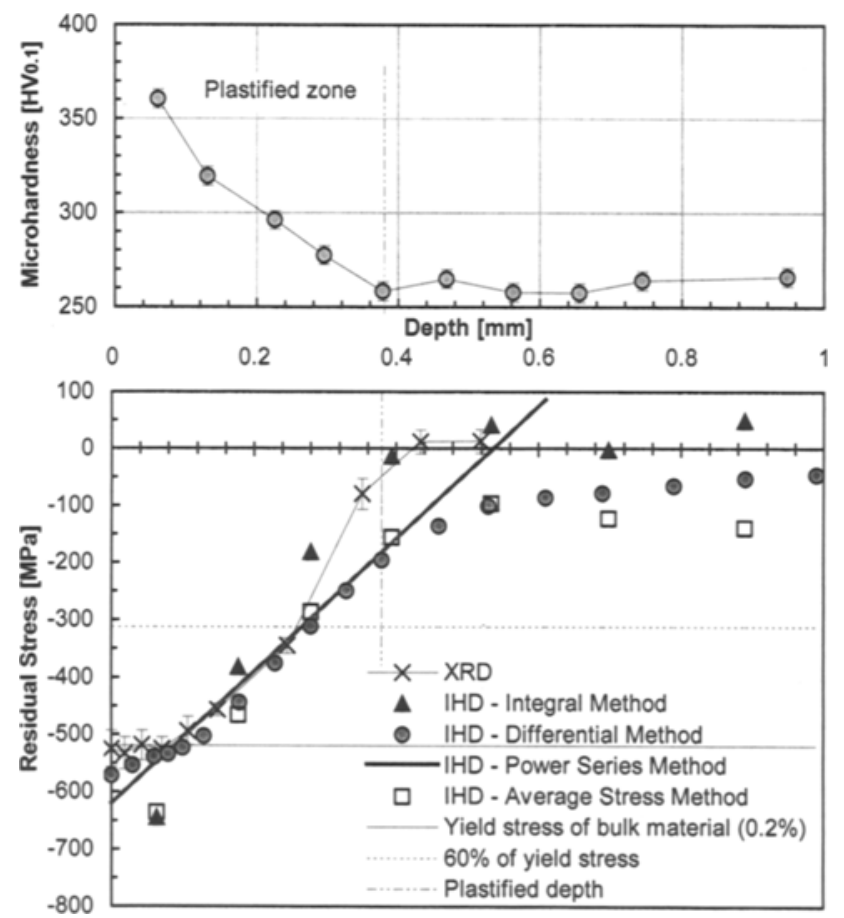

Fig. 5-Residual stresses, microhardness profile and plastified depth in specimen 4 (AISI 9255): comparison between incremental hole-drilling (IHD) and X-ray diffraction (XRD) results approximation of the shot-peening residual stresses analyzed in this work.

Table 3 summarizes the general observations of Figs. 2-6. The second column shows the plastified depth induced by the shot-peening treatment. For all specimens, it varies in the range of $0.26 \mathrm{~mm}$ to $0.44 \mathrm{~mm}$. The plastified depth tends to decrease with the increase of the elastic limit of the bulk material. The third column shows the maximum variation of the material's hardness from the interior to the surface, ranging from 3 percent for specimen 5 to 45 percent for specimen 2 . These variations quantify the work hardening attained by the shot-peened material and will be used to estimate the near-surface yield strength. The last column of Table 3 presents the ratio between the maximum compressive residual stress measured by XRD and the yield strength of the respective bulk material. Theoretically, ignoring the strainhardening effect, IHD could be correctly applied only in the case of specimen 5 . In all other cases, an overestimation of the real residual stresses as a consequence of the plasticity effect had to be expected, since the respective residual stresses exceed 60 percent of the bulk material's yield strength.

The results obtained in this work, however, indicate that the hole-drilling method can still be used to evaluate shot-peening residual stresses, even in cases where residual stresses are above the yield strength of the respective bulk material. In these cases, the strain hardening due to the surface treatment has to be taken into consideration. The results obtained for specimens 1, 2 and 4 (Figs. 2, 3 and 5) clearly confirm this point of view when the XRD results are compared with those obtained by IHD. Clear differences between both measurement methods are found in the entire analyzed depth only for specimen 3 (Fig. 4). In this case, the compressive residual stresses obtained by all the IHD methods
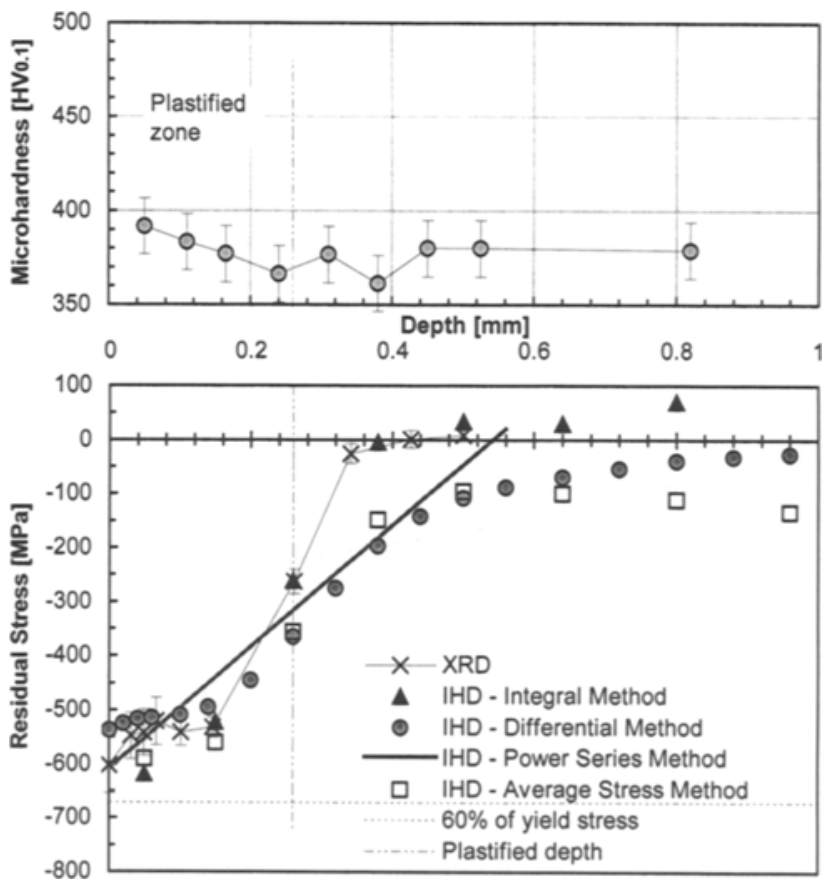

Fig. 6-Residual stresses, microhardness profile and plastified depth in specimen 5 (AISI 4337): comparison between incremental hole-drilling (IHD) and X-ray diffraction (XRD) results 


\begin{tabular}{cccc}
\hline Steel (AISI) & Plastified Depth $(\mathrm{mm})$ & $\Delta H / H(\%)$ & $\hat{\sigma}_{X R D} / \sigma_{y 0.2}(\%)$ \\
\hline $1-1045$ & 0.34 & 29 & 126 \\
$2-(420)$ & 0.44 & 45 & 128 \\
$3-3415$ & 0.42 & 19 & 115 \\
$4-9255$ & 0.38 & 38 & 103 \\
$5-4337$ & 0.26 & 3 & 54
\end{tabular}

have values that are distinctively higher than those obtained by XRD.

\section{Discussion}

\section{Analysis of the Plasticity Effect on IHD Results}

For a systematic analysis of the differences between IHD and XRD residual stress results and the expected occurrence of the plasticity effect, which leads to the overestimated IHD results, a mean value of the residual stresses obtained in the range of $0 \mathrm{~mm}$ to $0.1 \mathrm{~mm}$ will be considered. In Table 4, respective mean values for each IHD calculation method are given as a percentage of the corresponding XRD mean values.

The attainable precision of the IHD method in determining near-surface residual stresses can be estimated by looking first at the results of specimen 5. In this case, any influence of the plasticity effect can be excluded due to the already very high yield strength of the bulk material. Whereas the integral and the average stress methods overestimate the $\mathrm{XRD}$ residual stresses by around 10 percent, the differential method determines a value 6 percent lower. This tendency to have nearly identical mean values for the average stress and the integral methods, and smaller values for the differential method, can also be observed for the other specimens. The results of the power series method appear to be close to those of the differential method.

The greatest discrepancies between the IHD and XRD results occurred in the case of specimen 3 , where the mean residual stress values determined by IHD are between 27 percent (differential method) and 55 percent (integral method) higher than the XRD value. Considering merely the ratio of the maximum residual stress determined by XRD to the bulk material's yield strength, the strongest influence of the plasticity effect was expected for specimens 1 or 2 (cf. Table 3). Instead, it seems that the very low strain-hardening capacity of specimen 3 is decisive for the plasticity effect to occur. Microhardness variation amounts to only 19 percent (cf. Table 3) compared with 29 percent and 45 percent for specimens 1 and 2, respectively. Tensile tests also showed a lower strain-hardening coefficient $(0.17)$ compared with specimens $1(0.27)$ and $2(0.21)$ (see Table 1). For specimen 3, the combination of a low yield strength and the small strain-hardening capacity of the material obviously enabled local yielding due to local stress concentration, resulting in the expected overestimation of residual stresses by IHD. On the other hand, for specimen 2 (Fig. 3), showing similar yield strength and high XRD residual stress values below the surface, the maximum hardness variation is $\mathbf{4 5}$ percent, which is more than twice as much as for specimen 3 (19 percent). In this case, IHD residual stress overestimation amounts to only 8 percent (differential method) and 32 percent (integral method), respectively. Here, the effect of plastic yielding around the hole has obviously been weakened due to the strong increase of the yield strength of the material layers close to the surface. Similarly, the good agreement of XRD and $\mathrm{IHD}$ results for specimens 1 and 4 can be explained. Additionally, in the case of specimen 1 (cf. Fig. 2), residual stresses determined by XRD drop immediately below the surface to a level close to the bulk material's yield strength, thus also rendering the plasticity effect less likely than if only the XRD maximum surface value were considered. Obviously, after shot peening, the yield strength of the bulk material does not itself give sufficient information on possible plastic yielding around the hole. The material's strain-hardening behavior should be known and taken into account.

\section{Estimating the Strain-hardening Influence}

To confirm and anticipate whether the plasticity effect can influence the results of IHD, Cahoon's ${ }^{21}$ equation was applied to estimate the yield strength of the shot-peened material close to the surface using microhardness measurements. A minimum depth of $50 \mu \mathrm{m}$ to $70 \mu \mathrm{m}$ was imposed to avoid edge effects on hardness tests, which were carried out on the cross section of all shot-peened samples. In a first step, the validity of Cahoon's equation was verified. Therefore, the yield strength was calculated directly from the measured hardness values of the bulk material and compared with the 0.2 percent offset yield strength obtained from the tensile tests (see Table 5). The fourth column of Table 5 shows the respective discrepancies. A maximum error of 14 percent was observed in the case of specimen 3 . These differences may be partly due to a small variation of the constant $c$, which was used to relate the mean contact pressure of Vicker's hardness indentations to the representative yield strength. For most metallic materials, $c=2.8$ is considered to be valid and was therefore used here. In all other cases, the observed errors were even below 8 percent, showing the validity of the applied equation and allowing a satisfactory estimation of the strain-hardening effect.

Thus, based on the proportionality between hardness and yield strength stated in Cahoon' ${ }^{21}$ equation, the increased local yield strength $\sigma_{y}^{*}$ can be easily determined using the yield strength of the bulk material $\sigma_{y 0.2}$ and the relative variation of the microhardness $\Delta H / H$, writing the equivalent formulation $\sigma_{y}^{*}=\sigma_{y 0.2} \cdot(1+\Delta H / H)$. Respective results obtained for the maximum hardness variation of each specimen are shown in the last column of Table 5.

Using the empirical procedure presented above, it is possible to estimate the ratio between XRD residual stress and the local yield strength of the shot-peened material as a function of the distance to the surface. This was carried out for each maximum hardness value using a corresponding average XRD residual stress value that was determined by interpolation over the depth range of the hardness indentation (see Table 6). The second column of Table 6 shows the respective interpolated residual stress values for all specimens. In the 
TABLE 4-COMPARISON BETWEEN INCREMENTAL HOLE-DRILLING (IHD) AND X-RAY DIFFRACTION (XRD) MEAN RESIDUAL STRESS RESULTS (EVALUATION DEPTH 0-0.1 mm)

\begin{tabular}{ccccc}
$\begin{array}{c}\text { Steel } \\
\text { (AlSI) }\end{array}$ & $\begin{array}{c}\bar{\sigma}_{I H D} / \bar{\sigma}_{X R D}(\%) \\
\text { Integral Method }\end{array}$ & $\begin{array}{c}\bar{\sigma}_{I H D} / \bar{\sigma}_{X R D}(\%) \\
\text { Differential Method }\end{array}$ & $\begin{array}{c}\bar{\sigma}_{I H D} / \bar{\sigma}_{X R D}(\%) \\
\text { Power Series Method }\end{array}$ & $\begin{array}{c}\bar{\sigma}_{I H D} / \bar{\sigma}_{X R D}(\%) \\
\text { Average Stress } \\
\text { Method }\end{array}$ \\
\hline $1-1045$ & 109 & 91 & 92 & 109 \\
$2-(420)$ & 132 & 108 & 112 & 127 \\
$3-3415$ & 155 & 127 & 128 & 149 \\
$4-9255$ & 124 & 103 & 107 & 123 \\
$5-4337$ & 112 & 94 & 101 & 107
\end{tabular}

TABLE 5-ESTIMATE OF THE MATERIAL'S YIELD STRENGTH FROM HARDNESS DATA

$\begin{array}{ccccc} & & \sigma_{y}=(H / 3) & \sigma_{y}^{*}=\sigma_{y 0.2} \\ (1+\Delta H / H) & & (1+1)^{m-2}(\mathrm{MPa}) \\ \text { Steel } & \sigma_{y 0.2} \text { (MPa) } & \begin{array}{c}\text { Direct Estimate } \\ \text { from Hardness }\end{array} & \begin{array}{c}\text { Error } \\ (\%)\end{array} & \begin{array}{c}\text { (MPa) Estimate } \\ \text { Based on } \sigma_{y 0.2}\end{array} \\ \text { (AISI) } & \text { Tensile Tests } & 413 & -0.5 & 535 \\ 1-1045 & 415 & 444 & +4.5 & 616 \\ 2-(420) & 425 & 508 & +14 & 530 \\ 3-3415 & 445 & 478 & -8 & 718 \\ 4-9255 & 520 & 1058 & -5.5 & 1154\end{array}$

TABLE 6-ESTIMATE OF THE RATIO BETWEEN X-RAY DIFFRACTION (XRD) RESIDUAL STRESS AND YIELD STRENGTH OF A SHOT-PEENED MATERIAL

\begin{tabular}{|c|c|c|}
\hline $\begin{array}{l}\text { Steel } \\
\text { (AISI) }\end{array}$ & $\begin{array}{c}\widetilde{\sigma}_{X R D}(\mathrm{MPa}) \\
\text { Interpolated for HV Maximum }\end{array}$ & $\begin{array}{c}\widetilde{\sigma}_{X R D} / \sigma_{y}^{*}(\%) \\
\text { Estimate }\end{array}$ \\
\hline $\begin{array}{l}1-1045 \\
2-(420) \\
3-3415 \\
4-9255 \\
5-4337\end{array}$ & $\begin{array}{l}418 \\
504 \\
471 \\
523 \\
542\end{array}$ & $\begin{array}{l}78 \\
82 \\
89 \\
73 \\
47\end{array}$ \\
\hline
\end{tabular}

final column, the percentage values of the ratio between the $\mathrm{XRD}$ residual stresses and the estimated local yield strength are given, making it possible to assess the applicability of the IHD method. These values were determined for an average depth of $60 \mu \mathrm{m}$ and can be used to explain the discrepancies verified between the XRD and IHD results shown in Table 4. Now, the highest discrepancies are observed for the highest ratios of residual stress to local yield strength.

Our results indicate that microhardness indentations can be used to predict material strain-hardening behavior, allowing a criterion for the reliability of IHD values to be established. With regard to the results presented in Table 6 , the plasticity effect clearly becomes relevant when the existing maximum residual stresses are higher than about 80 percent of the corresponding local yield strength of the shot-peened material. A simple criterion for the validity of obtained residual stress values can be written as follows, using only the yield strength of the bulk material and the relative maximum variation of the microhardness:

$$
\sigma^{R S} \leq k \cdot \sigma_{y}\left(1+\frac{\Delta H}{H}\right) \text { with } 0.6<k<0.8
$$

where $k$ depends on the residual stress state and distribution and on the calculation method applied.

\section{Comparison between IHD Calculation Procedures}

In deeper layers, a good agreement between the results of IHD, using the integral method, ${ }^{18,26}$ and XRD results can be observed in all cases. On the other hand, the differential method $^{16}$ and the average stress method ${ }^{15,17}$ present large differences compared with the XRD results in those layers.
These differences cannot be explained by the plasticity effect, since they also occur in the case of specimen 5 (Fig. 6), where no influence of the plasticity effect on IHD results can be expected (see Tables 3 and 6). At the depth where the XRD results reach zero, the differential and the average stress methods still show compressive residual stresses of about $-200 \mathrm{MPa}$. These discrepancies can be related to the theoretical shortcomings of these evaluation methods, which become more relevant at greater depths. The differential method assumes the strain relaxation caused by the stresses existing in the previous increments to be the consequence of the already stress-free increments. The average stress method disregards the fact that the stresses in the material closer to the surface contribute much more to the relieved surface strain than do the stresses farther from the surface. These theoretical simplifications obviously lead to increasing errors at greater distances from the surface. The experimental results obtained for shot-peened specimens indicate that the differential method and the average stress method can only be used correctly up to a depth of about $0.3 \mathrm{~mm}$. It should be noted, however, that the IHD is generally limited to a depth equal to the hole radius. $16,18,28,32$ The decreasing sensitivity of surface strain relief to the stress relaxation farther from the surface leads to a stronger influence of measurement errors. For the chosen measurement conditions, this limit is close to $0.9 \mathrm{~mm}$.

Considering the results obtained close to the surface, the integral method and the average stress method values always present an overestimation compared with the differential method, which shows the best agreement with the XRD values. This difference becomes more pronounced when the plasticity effect influences IHD results, as verified in 
specimens 2 and 3 (Figs. 3 and 4). The lower accuracy in determining the first increment size combined with the higher error sensitivity of these methods compared with the differential method can explain this effect. Besides, the differential method can be used with a better depth resolution. The power series method ${ }^{18,29}$ is best applied in cases where indepth nonuniform residual stresses can be approached by a linear distribution.

Comparison of XRD and IHD results is problematic when very strong residual stress gradients are present at the material's surface. This is due to the minimum increment size required for the hole-drilling method, allowing a reasonably accurate measurement of increment size and respective strain relaxation. Strong residual stress variation obviously cannot be detected when occurring within one increment. In these cases, the XRD method should be used. The IHD method, however, appears to be a suitable technique for characterizing in-depth shot-peening residual stresses.

\section{Conclusions}

Comparing results of the IHD method and the XRD technique, we have shown that the incremental hole-drilling method can be correctly used to measure residual stresses in shot-peened components, even if residual stresses exceed the yield strength of the bulk material. The strain hardening in the surface can obviously prevent plastic yielding to a great extent, normally already affecting hole-drilling results when residual stresses exceed 60 percent of the bulk material's yield strength. Nevertheless, even residual stresses amounting to almost 130 percent of the bulk material's yield strength could be determined in good agreement with XRD values. In this case, however, a high strain hardening was observed in the near-surface material layers. Consequently, for an assessment of the reliability of incremental hole-drilling results, the strain hardening caused by the shot-peening treatment has to be taken into account.

The microhardness variation between the bulk material and the surface was used to quantify the respective strain hardening and to calculate a corresponding local yield strength close to the surface where maximum residual stress values had been detected. Then, determining a local ratio of the residual stress to the corresponding local yield strength, an empirical criterion could be set up to predict the occurrence of the plasticity effect. A distinct overestimation of residual stresses evaluated by incremental hole drilling is observed when the residual stresses exceed 80 percent of the yield strength of the shot-peened layer. For smaller ratios, tolerable errors were obtained, although the error size also depends on the evaluation method applied. These findings were obtained for shot-peening residual stresses, but they can certainly be transferred to similar residual stress states, when maximum residual stress values and respective relative hardness variations are considered.

Furthermore, the main IHD calculation procedures can be evaluated by comparing the experimental results. The average stress method is only an approximate method. When residual stresses have almost linear distributions, the power series method can be used. The differential method showed best agreement with XRD values close to the surface. In addition, it appears to be less sensitive to the plasticity effect. In deeper layers, the integral method is definitely the most appropriate calculation procedure, especially when strong stress gradients exist.

\section{Acknowledgments}

The authors gratefully acknowledge the financial support of BMBF-Bundesministerium für Bildung und Forschung Germany and JNICT-Fundação para a Ciência e Tecnologia Portugal for bilateral cooperation, which made this work possible.

\section{References}

1. Belassel, M., Lebrun, J.L., Denis, S., Gautier, E., and Bettembourg, J.P., "Effect of Thermal and Mechanical Loading on the Generation of Macro and Micro Stresses in Eutectoid Steel," Proceedings of the 4th International Conference on Residual Stresses, Baltimore, MD, 392-401 (1994).

2. Niku-Lari, A., Lu, J., and Flavenot, J.F., "Measurement of Residual Stress Distribution by the Incremental Hole-drilling Method," J. Mech. Working Tech., 11, 165-188 (1985).

3. Chant, M.J., Griffith, R.A., and Miles, L., "Comparison of Two Methods of Measuring Residual Stresses Arising from Surface Treatment," $J$. Mech. Working Tech, 8, 181-191 (1983).

4. Le Calvez, C., Lebrun, J.L., Cluzeau, C., and Harcouet, P., "Industrial Optimisation of Stress Gradient Determination by X-ray Diffraction and Incremental Hole-drilling on Beryllium and Aluminium Alloy," Recent Advances in Experimental Mechanics, S. Gomes et al., eds., A. A. Balkema, Rotterdam, 751-756 (1994).

5. Fathallah, R., Cao, W., Castex, L., Webster, P.S., Ezeilo, A., Webster, G.A., and Webster, P.J., "Comparison of Residual Stresses Determined by $X$-ray Diffraction, Neutron Diffraction and the Hole Drilling Method in Aerospace Shot-peened Materials," Proceedings of the 4th International Conference on Residual Stresses, Baltimore, MD, 834-843 (1994).

6. Lu, J. and Flavenot, J.F., "Applications of the Incremental Holedrilling Method for Measurement of Residual Stress Distribution," Exp. Techniques, 13, 18-24 (1989).

7. Baron, H.U., "Kombinierter Einsatz der Röntgenbeugung und der Bohrlochmethode bei der industriellen Eigenspannungsermittlung," Residual Stresses, Proc. European Conference on Residual Stresses 1992, Oberursel, Deutsche Gesellschaft für Materialkunde, 269-278 (1993).

8. Zhu, W.X. and Smith, D.J., "Residual Stresses by Hole-drilling in Curved Components," Recent Advances in Experimental Mechanics, $S$. Gomes et al., eds., A. A. Balkema, Rotterdam, 777-782 (1994).

9. Jo, J., Hendricks, R.W., Swanson, R.E., and Foutz, R.V., "Residual Stresses in Railroad Car Wheels," Adv. X-ray Anal., 34, 611-622 (1991).

10. Lu, J., Bouhelier, C., Lieurade, H.P., Baralle, D., Miege, B., and Flavenot, J.F., "Study of Residual Welding Stress Using Step-by-step Hole Drilling and $X$-ray Diffraction Method," Welding in the World, 33 (2), 118128 (1994).

11. Villard, C., Viola, A., Zeller, E., Castellucci, P., and Duchazeaubeneix, J.M., "Techniques de Mésures de Contraintes Résiduelles: Contribution à l'Étude de l'Amélioration de la Tenue en Fatigue d'Alliages Utilisés en Aéronautique," J. de Physique IV, 6, 239-249 (1996).

12. Kornmeier, M., "Analyse von Abschreck-und Verformungseigenspannungen mittels Bohrloch-und Röntgenverfahren," PhD thesis: Institut für Werkstoffiechnik, Universität Gh Kassel (1999).

13. Beaney, E.M. and Procter, E., "A Critical Evaluation of the Center Hole Technique for the Measurement of Residual Stresses," Strain, 10, 7-15 (1974).

14. Beaney, E.M., "Accurate Measurement of Residual Stress on any Steel Using the Center Hole Method," Strain, 12, 99-106 (1976).

15. "Measurement of Residual Stresses by the Hole-drilling Strain Gage Method," Technical Note No. TN-503-4, Vishay-Measurements Group Inc., $1-19(1993)$.

16. Schwarz, T. and Kockelmann, H., "Die Bohrlochmethode-ein für viele Anwendungsbereiche optimales Verfahren zur Experimentellen Ermittlung von Eigenspannungen," HBM, Messtechnische Briefe, 29 (2), 33-38 (1993).

17. Nickola, W.E., "Practical Subsurface Residual Stress Evaluation by the Hole Drilling Method," Proceedings of the SEM Spring Conference on Experimental Mechanics, New Orleans, 47-58 (1986).

18. Schajer, G.S., "Measurement of Non-uniform Residual Stress Using the Hole-drilling Method," ASME J. Eng. Mat. Tech., 110, 338-343, 344349 (1988).

19. Tabor, D., "A Simple Theory of Static and Dynamic Hardness," Proc. Roy. Soc. Lon. A, 192, 247-274 (1948).

20. George, R.A., Dinda, S., and Kasper, A.S., "Estimating Yield Strength from Hardness Data," Metal Prog., 30-35 (May 1976). 
21. Cahoon, J.R., Broughton, W.H., and Kutzak, A.R., "The Determination of Yield Strength from Hardness Measurements," Metall. Trans., 2 , 1979-1983 (1971).

22. Mathar, J., "Ermittlung von Eigenspannungen durch Messung von Bohrlochverformungen," Archiv für das Eisenhüttenwesen, 6, 277-281 (1933).

23. ASTM E837-94a, "Standard Test Method for Determining Residual Stresses by the Hole-drilling Strain-gage Method," Annual Book of ASTM Standards, American Society for Testing and Materials, Philadelphia, 1-7 (1994).

24. Beghini, M., Bertini, L., and Raffaelli, P., "Numerical Analysis of Plasticity Effects in the Hole-drilling Residual Stress Measurement," J. Test. Eval., 22, 522-529 (1994).

25. Gibmeier, J., "Untersuchung plastischer Dehnungsanteile bei der Bohrlochmethode-FEM-Modellierung experimentell ermittelter Dehnungsverläufe," Diplomarbeit, Institut für Werkstofftechnik, Universität Gh Kassel (1998).

26. Bijak-Zochowski, M., "A Semi-destructive Method of Measuring Residual Stresses," VDI-Berichte, 313, 469-476 (1978).

27. Flaman, M.T. and Manning, B.H., "Determination of Residual-stress Variation with Depth by the Hole-drilling Method," EXPERIMENTAL MECHANICS, 25, 205-207 (1985).

28. Kelsey, R.A., "Measuring Non-uniform Residual Stresses by the Hole
Drilling Method," Proc. Soc. Exp. Stress Anal., 14, 181-194 (1956).

29. Schajer, G.S., "Application of Finite Element Calculations to Residual Stress Measurements," ASME J. Eng. Mat. Tech., 103, 157-163 (1981).

30. Wern, H., "Measurement of Non-uniform Residual Stresses Using the Hole Drilling Method-A New Integral Formalism," Strain, 31(2), 63-68 (May 1995).

31. Kockelmann, H. and Schwarz, T., "Vergleich Praktizierter Auswerteverfahren der Bohrlochmethode," Experimentelle Spannungsanalyse, Kolloquium Kölln 1993, GMA-Bericht, 22, 93-103 (1993).

32. Lu, J., ed., Handbook of Measurement of Residual Stresses, Society for Experimental Mechanics, Bethel, CT, 5-34, 71-131 (1996).

33. Flaman, M.T., Mills, B.E., and Boag, J.M., "Analysis of Stressvariation-with-depth Measurement Procedures for the Center-hole Method of Residual Stress Measurement," Exp. Techniques, 11, 35-37 (1987).

34. Schajer, G.S. and Altus, E., "Stress Calculation Error Analysis for Incremental Hole-drilling Residual Stress Measurements," ASME J. Eng. Mat. Tech., 118, 120-126 (1996).

35. Macherauch, $E$. and Müller, $P$., "Das $\sin ^{2} \psi$-Verfahren der röntgenographischen Spannungsmessung," Zeitschrift für angewandte Physik, 13, 305-312 (1961).

36. Flaman, M.T., "Investigation of Ultra-high Speed Drilling for Residual Stress Measurements by the Center Hole Method," EXPERIMENTAL MECHANICS, 22, 26-30 (1982). 